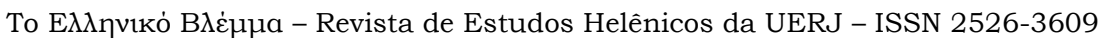

Separata - Artur Gouvêa - Programa de Pós-Graduação em Música - Universidade Federal do Rio de Janeiro

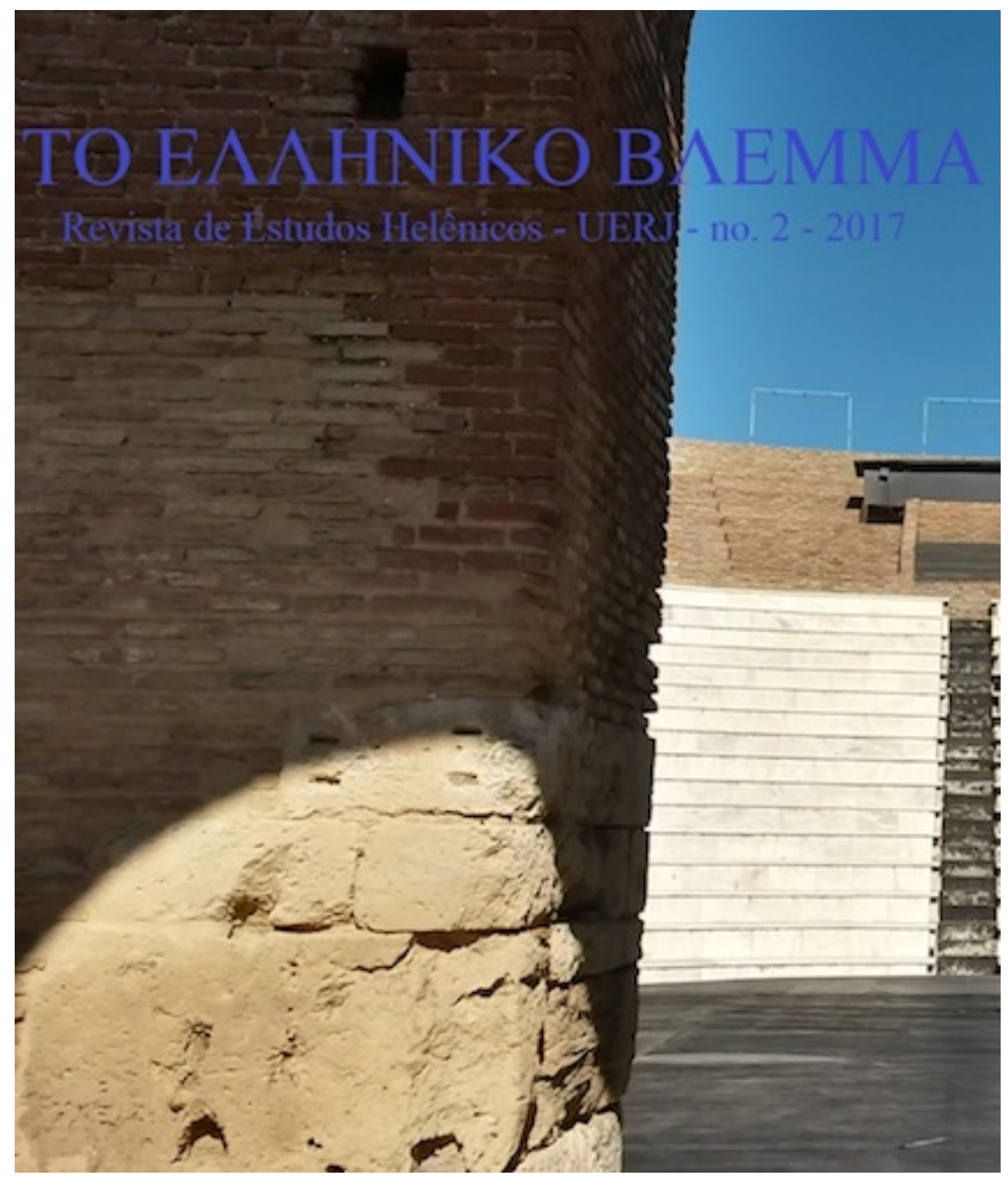




\section{Ritmo em Aristóxeno}

Artur Gouvêa

Programa de Pós-Graduação em Música - UFRJ

\section{Resumo}

Este trabalho apresenta pesquisa, tradução e comentários sobre o texto Elementos de ritmo, escrito pelo antigo estudioso da música Aristóxeno de Tarento, com o intuito de elucidar questões concernentes aos termos por ele utilizados para descrever os fenômenos musicais relacionados à organização do tempo e, consequentemente, aos agrupamentos das durações, tentando traçar um paralelo entre a forma de responder a esses fenômenos no período antigo e hodiernamente. Para tal, tentar-se-á localizar de forma suscinta Aristóxeno no contexto de seu tempo e provocar discussões a partir de excertos traduzidos do texto grego estabelecido por Christopher Marchetti que evidenciarão o choque entre o discurso antigo, presente no texto de Aristóxeno, e o discurso que parte da vivência contemporânea particular do autor deste documento.

Palavras-chave: Aristóxeno - Música - Ritmo

\section{Abstract}

This work presents a research, translation and comments on the text Elements of rhythm written by the ancient music scholar Aristoxenus of Tarentum in order to elucidate questions concerning the terms used by him to describe the musical phenomena related to the organization of time and consequently the groupings of durations, trying to draw a parallel between the way of responding to these phenomena in the ancient period and nowadays. To this end, it will be tried to locate Aristoxenus in the context of his time and to provoke discussions from translated excerpts taken from the Greek text as established by Christopher Marchetti. Such discussions will theoretically evidence the clash between the old discourse, present in Aristoxenus, and the discourse that comes from the contemporary experience of the author of this document.

Keywords: Aristoxenus - Music - Rithm

Nascido entre 375 e 360 A.C., em Tarento, foi um filósofo e teórico da Música. Foi a figura mais importante e influente no campo da teoria musical na Grécia Antiga, conhecido como "o músico". Viveu durante e depois da era de Alexandre, o Grande. Era filho de músico, chamado Mnesias. Começou a aprender música com seu pai, depois foi aluno de Lamprus, em Matineia, em sua juventude. Ao voltar para a região da Itália, estudou com Xenófilo, pensador pitagórico de quem ficou amigo. Sabe-se que algum tempo depois foi a Corinto, onde conheceu Dionísio, tirano de Siracusa, que estava por lá exilado. Por fim, tornou-se pupilo de Aristóteles, no Liceu em Atenas. Aparentemente teve importante posição entre os pupilos, inclusive com expectativas de ser o sucessor de seu mestre no Liceu.

Foi um escritor prolífico, produzindo mais de 450 volumes versando sobre música, filosofia, história e educação em geral. Entre suas obras, tratados sobre diversos assuntos musicais: Elementos de harmonia (em três livros, a maior parte preservada); Elementos de ritmo (tendo restado um importante fragmento, sobre o qual nos debruçaremos); Sobre 
música; Sobre melopeia; Sobre as notas; Sobre a escuta musical; Sobre o tempo primário; Sobre instrumentos, ou Sobre aulo e instrumentos; Sobre o interior do aulo; Sobre aulética; Sobre o coro da tragédia; e uma obra da qual o fragmento rítmico de Oxirrinco é derivado. A maior parte desses volumes se perdeu, mas foram descobertos extratos deles em referências frequentes de Plutarco, Ateneu, Porfirio e outros escritores. Detalhes valiosos de suas doutrinas teóricas e de ensino são encontradas principalmente em Isagoge, de Cleônides e Tratado sobre música, de Aristides Quintiliano. Em Gaudêncio e Bacchio também se acha parte dessas doutrinas.

A educação de Aristóxeno sob a doutrina aristotélica pode dizer algo sobre seu discurso. Aristóteles é notável pela concisão de pensamento e busca das generalidades das coisas. Levou o dualismo de Platão, presente na oposição entre o sensível e o inteligivel, à articulação metafísica do pensamento. Criou procedimentos para os processos epistemológicos que desenvolveram as Ciências Naturais. Curiosamente, a articulação metafísica tem origem no princípio musical da consonância, onde a Fundamental ideal é a que abarca todas as outras alturas. Se pudéssemos ouvir, por exemplo, o som de uma frequência de $1 \mathrm{~Hz}$, teríamos todas as outras frequências dentro de seus domínios físicos. Curiosamente também, até onde se sabe, Aristóteles não era grande conhecedor da arte da Música. Dos escritos que sobreviveram ao tempo, restaram somente descrições e classificações pouco esclarecedoras de questões musicais, de modo específico. O discurso de Aristóteles é algo bem afastado do que se pode chamar de musical. Mas as tendências racionalizantes, generalizantes e classificatórias do pensamento metafísico ajudaram a criar os textos de Aristóxeno de forma a guardar ainda uma relação íntima com o leitor e facilitar o entendimento daquela forma de classificação.

A forma científica está em posição de destaque na atualidade, assim como a articulação metafísica de pensamento, que generaliza, posto que se especialize cada vez mais. Os termos utilizados por Aristóxeno muitas vezes aproximam a música a relações matemáticas e de forma, mas as traduções modernas muitas vezes escondem essas relações, pois as novas línguas tendem a relacionar várias palavras a um mesmo significado. Tomemos como exemplo a palavra ritmo. Seu sentido está intimamente ligado ao movimento. Allen Winold nos dá uma perspectiva um pouco diferente, embora também ligada a movimento:

Quando consideramos que a origem do significado da palavra ritmo é fluxo, como no fluxo de um rio, somos lembrados de uma das maiores armadilhas em qualquer consideração de ritmo na Música. Nós nunca poderemos parar o fluxo de um rio para examinar e descrevê-lo, pois senão não teremos mais um fluxo, mas ainda somente água. (WINOLD, 1975, 208.) (Tradução nossa.)

Émile Benveniste mostra que esse sentido nos é dado pelo menos desde o início da gramática comparada e ligaria a palavra grega à noção de "fluir" com uma ligação ao movimento das ondas. Mas identifica erro semântico nessa abordagem e acha as origens da palavra no atomismo de Leucipo e Demócrito, usada como termo técnico para suas doutrinas. Aristóteles, que foi responsável por boa parte dos fragmentos pelos quais sobreviveram os trabalhos de Demócrito, dá, segundo Benveniste, a sua significação exata:

Segundo ele, as relações fundamentais entre os corpos estabelecemse pelas suas relações mútuas, e essas diferenças se reduzem a três - rismos, diathige, trope - que Aristóteles interpreta da seguinte maneira:(...) "As coisas diferem pelo rismos, pela diathige e pela trope; O rismos é o schema ("forma"); a diathige ("contato") é a radzis ("ordem"); e a trope ("reviravolta") é a thesis ("posição").(Metaph, 985, b 4). (BENVENISTE, 1976, 363.) 
O linguista segue em suas investigações para trazer à tona algo que se aproxima do sentido originário de ritmo. De "fluir", chegará até o sentido de "forma movente", apresentando as diferenças que deixamos de considerar ao fazer a relação direta com que é aceito pelo senso comum. Note-se que, em certo momento, a palavra rysmos se modifica um pouco, para rythmos. Isso se deve a semelhanças naturais entre os fonemas /s/ e $/ \theta /$, que podem ter cambiado de acordo com a região.

Sobressai desse importante texto que rysmos significa schema, "forma", o que Aristóteles confirma, na sequência desse passo, por meio de um exemplo tomado a Leucipo. Ilustra essas três noções aplicando-as respectivamente à "forma", à "ordem" e à "posição" das letras no alfabeto. A difere de $\mathrm{N}$ pelo schema (ou rysmos), AN difere de NA pela radzi, e I difere de $\mathrm{H}$ pela thesis. Conservemos dessa citação que rysmos tem por equivalente schema. (...)

Se procurarmos os poetas líricos, é ainda mais cedo, desde o VII século, que vemos aparecer rythmos. É tomado, como schema ou tropos, para definir "forma" individual e distintiva do caráter humano (...)

As citações são amplamente suficientes para estabelecer: $1^{\circ}$ que rysmos nunca significa "ritmo" desde a origem até o período ático; $2^{\circ}$ que nunca se aplica ao movimento regular das ondas; $3^{\circ}$ que o sentido constante é "forma distintiva, figura proporcionada, disposição", nas mais variadas condições de emprego, aliás. Igualmente os derivados ou os compostos, nominais ou verbais, de rythmos sempre se referem apenas à noção de "forma". Essa foi a significação exclusiva de rythmos em todos os gêneros escritos até a época na qual interrompemos as nossas citações.

Estabelecido este sentido, é possivel e necessário precisá-lo. Para "forma", há em grego outras expressões: schema, morphé, eidos, etc. das quais rythmos deve de algum modo distinguir-se, melhor do que pode indicá-lo a nossa tradução. A própria estrutura da palavra rythmos deve ser interrogada. (...) Quando os escritores gregos interpretam rythmos como schema, quando nós mesmos o traduzimos por "forma", trata-se, nos dois casos, apenas de uma aproximação. Entre schema e rythmos, há uma diferença; schema com relação a echo, "eu (me) contenho" (cf., quanto à relação, o lat. habitus: habeo) se define como uma "forma" fixa, realizada, posta de algum modo como um objeto. Ao contrário rythmos, segundo os contextos onde aparece, designa a forma no instante em que é assumida por aquilo que é movediço, móvel, fluido, a forma daquilo que não tem consistência orgânica: convém ao pattern de um elemento fluido, a uma letra arbitrariamente modelada, a um peplo que se arruma quando quer, à disposição particular do caráter ou do bom humor. É a forma improvisada, momentânea, modificável. (BENVENISTE, 1976, 365-368).

Os tratados de música escritos em forma de manual são tendência pelo menos até o século XX. São provavelmente inspirados na forma concisa de escrita de Aristóxeno e não só refletem uma vontade de aproximação entre a maneira de expor os conhecimentos sobre música e as outras formas de conhecimento. Como se sabe, na Idade Média a música fazia parte do Quadrivium, sendo parte trivial (ou melhor, "quadrivial") da formação do 
erudito. Boécio (480-525 D.C.), um dos mais respeitados estudiosos de sua época, era reconhecidamente aficionado por Aristóteles, tendo traduzido boa parte de seus textos. Seu livro De Institutione Musica fazia parte do material de estudos provavelmente usado por ele ao ensinar a seus alunos as matérias do quadrivio e é uma compilação de conhecimentos antigos; boa parte do que concernia a nomes e números era intimamente relacionada ao texto de Aristóxeno. Essa abordagem musical inspirou outros autores músicos e ficou em voga pelo menos até a reforma promovida por Gregório Magno, no século X. Mas a forma de escrever sobre música, classificando os gêneros e listando as formas, permaneceu.

Aparentemente a forma dos tratados obedecia a uma forma geral de discurso escrito, que se aproximava mais da ciência e filosofia que da poesia. Premissas e certezas eram necessárias para a legitimação do conhecimento sobre música. Sua origem, provavelmente, é mais antiga que o texto de Aristóxeno ou Aristóteles. Encontramos em Platão um marco do pensamento dicotômico, que acabou por evoluir para o discurso científico. Eric Havelock (1994) nos diz que a passagem da oralidade para escrita nas artes está ligada a um incômodo quanto à subordinação dos homens em relação ao místico, ou seja, aquilo que estaria além do controle humano ${ }^{1}$.

Com o tempo a necessidade de o que está escrito ter uma rigidez métrica e rítmica foi se perdendo, assim como a necessidade de aliar o que era dito no poema a uma melodia e movimentos corporais específicos. Desse modo a arte das musas foi pouco a pouco se desmembrando em várias "formas" de arte e cada musa foi sendo atrelada a uma dessas formas. Este lento processo nos permitiu, nos dias de hoje, conceber as "artes" separadamente, reflexo do advento da escrita. Na verdade, trata-se de uma decisão do homem primar pela escrita como processo de memoração em substituição ao processo anterior, legado a um personagem que em subserviência a um fazer místico, privava toda pólis do controle sobre sua memória. Isto é, a cultura e a história faziam parte de algo que necessitava ser dito pelas musas (HAVELOCK, 1996).

Daí o incômodo a que Havelock se refere. A escrita passou a apontar aquele que escrevia como o condutor dessa história, conhecedor dessa cultura. Passamos a nos reconhecer como autores de nossa própria história. A mudança na noção de "verdade" também está intimamente ligada à transição da escrita. Instaurados pelo advento da escrita podem ser destacados outros reflexos dessa transição. A música tonal, como forma de música mais difundida, se dá de modo a apresentar a tensão. Resolvê-la é a atitude mais lógica.

\section{Elementos de ritmo}

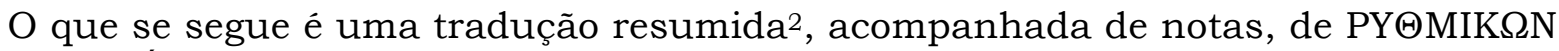
$\Sigma T O I X E I \Omega N ~ B '(R y t h m i k o n$ Stoicheion B), de Aristóxeno, e para tal utilizou-se o texto grego estabelecido por Christopher Marchetti (MARCHETTI, 2009).

\section{Aristóxeno}

\section{Elementos de ritmo $2^{3}$}

1. Que são muitas as naturezas do ritmo, quais são suas diferenças e a causa de compartilharem o nome, foi previamente discutido. O texto a seguir trata do ritmo relacionado à música.

\footnotetext{
$1 \mathrm{O}$ controle dos deuses diz respeito, também, à sua vontade determinante nos atos dos homens. Desse modo, não existe a vontade do homem, mas sim a Moira, destino; o Oráculo; a Esfinge; as musas, filhas de Mnemósine; os deuses e suas dádivas.

${ }^{2}$ Alguns trechos foram encurtados com a intenção de ressaltar os aspectos mais relevantes percebidos, sem estender demais o presente texto.

${ }^{3}$ Como esta seção compõe-se integralmente da tradução, optou-se por usar a formatação comum.
} 
2. Que é concernente aos intervalos de tempo e sua percepção já foi declarado; No entanto, será repetido agora, pois de alguma maneira esse é o princípio fundamental do estudo do ritmo.

3. Deve-se observar que há duas naturezas, a do ritmo e a do ritmizado, tão relativos entre si quanto a forma e aquele que é formado. ${ }^{4}$

4. Se um corpo assume formas variadas, se essas formas são organizadas diferentemente, seja em todas as partes ou algumas delas, então cada um dos objetos ritmizados recebe várias formas, não de sua própria natureza, mas pela natureza do ritmo. O mesmo texto, organizado em intervalos de tempo diferentes, assume variações, as quais são equivalentes às variações presentes na natureza do ritmo. Na mesma conta estão a melodia e qualquer outra coisa cuja natureza foi ser ritmizada pelo tipo de ritmo que é organizado em intervalos de tempo. 5

5. Deve-se daqui aplicar a percepção resguardando esta analogia, no empenho de ver, a respeito de cada coisa mencionada, de que tipo é o ritmo e o objeto ritmizado. ${ }^{6}$ Pois nenhum corpo que pode receber forma naturalmente é o mesmo que as formas, mas sim a forma é um arranjo das partes do corpo, decorrente de ter cada uma das partes de certa maneira, de onde é chamado forma. Assim, também o ritmo não é o mesmo que os objetos ritmizados, mas é o que os arranja, de uma maneira ou de outra, e fazendo-o assim respeitando os intervalos de tempo.

6. As coisas acima mencionadas se relacionam entre si também porque não vêm para ser eles mesmos. Para a forma, se aquilo que recebe não está presente, claramente não pode vir a ser. Da mesma maneira, ritmo não pode vir a ser na ausência daquilo que será ritmizado e que divide tempo, pois tempo não se divide sozinho, como dissemos acima, mas requer que algo o divida. Portanto, é necessário que o objeto ritmizado seja divisível em partes reconhecíveis, com as quais dividirá o tempo.

7. Essa formulação segue o que foi dito e o próprio fenômeno: o ritmo ocorre sempre que a distribuição dos intervalos de tempo assume algum arranjo definido, pois nem todo arranjo em intervalos de tempo é incluído entre os ritmos.

8. Assim, é crível, mesmo sem explicação, que nem toda organização em intervalos de tempo é rítmica. Mas deve-se induzir o pensamento por analogias e tentar aprender com elas, até que uma prova possa surgir da matéria em si.

Conhecidas por nós são as matérias concernentes à combinação de letras e intervalos musicais, pois nem ao falar combinamos letras de qualquer maneira, nem ao cantar, os intervalos. Em vez disso, há apenas alguns caminhos com os quais eles são combinados entre si, muitos deles em que a voz não é capaz de combinar em enunciado, nem a percepção aceitar, mas rejeitar. Pela mesma razão, uma melodia bem construída é feita em poucas formas, a mal construída, em um pouco mais.

Assim também aparecerão as coisas relativas aos intervalos de tempo: pois muitos são os arranjos e proporções que são claramente estranhos à percepção, e poucos são os apropriados a serem arranjados na natureza do ritmo.

O objeto ritmizado é, de certa forma, comum tanto à arritmia e ao ritmo, pois é naturalmente capaz de receber ambas as construções: o rítmico e o arrítmico. Basta dizer que o objeto ritmizado deve ser pensado como aquilo que é capaz de ser arranjado em todo tipo de intervalo de tempo e todo tipo de combinação.

9. O tempo é dividido pelos objetos ritmizados, por meio das partes de cada um. ${ }^{7}$ Os objetos são três: texto, melodia e movimento corporal (lexis, melos, kinesis somatike). Assim o texto dividirá o tempo com suas partes, tais como letras, sílabas, palavras, e coisas assim; a melodia o dividirá em notas, intervalos e escalas; o movimento corporal, em sinais e posições e qualquer outra parte de movimento.

\footnotetext{
${ }^{4} \mathrm{O}$ ritmo aqui está cruamente relacionado com forma, sem imagem poética de ondas ou de rio.

5 Então o autor assume que outras coisas além da melodia podem ser ritmizadas.

${ }^{6}$ Ritmo - rysmos; objeto ritmizado - rythmizomenon, rhythmizomena, pl.; a arte da composição do ritmo - rythmopeia.

Pode-se entendê-los, respectivamente, como forma; sujeito à forma; e organização das formas.

${ }^{7}$ Divisão do tempo pelos objetos, movimento corporal, melodia e texto.
} 


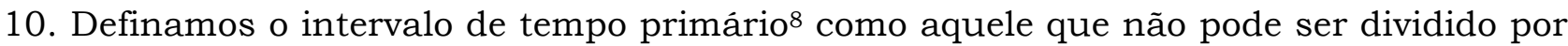
qualquer objeto ritmizado; O "diseme" é medido por dois desse, o "triseme" é medido por três, o "tetraseme" é medido por quatro. Os nomes de todas as durações restantes seguirá analogamente.

11. É preciso tentar entender o sentido do tempo primário desta forma: É característico das coisas que aparecem vivamente na percepção não tomar a velocidade de seus movimentos ao ponto de uma intensificação ilimitada, mas para os intervalos de tempo comprimidos, em que as partes dos objetos movidos são organizadas para ficarem fixas em algum lugar. Estou falando de coisas movidas, como a voz é movida falando e cantando e o corpo andando e dançando e executando o resto de seus movimentos.

12. Este intervalo de tempo, no qual de forma alguma podem ser colocadas duas notas, duas silabas, ou dois passos, nós chamaremos intervalo de tempo primário. Como a percepção vai entender isso ficará claro na discussão dos esquemas dos pés.

13. A respeito da prática da composição rítmica, falamos de um certo tempo não composto. Que a composição rítmica não é o mesmo que ritmo não é fácil deixar claro, mas confie na seguinte analogia. Como vimos, na natureza da melodia, que nem uma escala, modo ou gênero é a mesma coisa que a composição melódica, devemos supor o mesmo no que concerne a ritmos e composição rítmica. Veremos isso mais claramente à medida que prossegue a investigação.

14. Considerando a prática da composição rítmica, falaremos de um tempo não composto9; se esse tipo de duração de tempo for ocupado por uma sílaba, nota ou passo, a isso chamaremos de tempo não composto. Se a mesma duração é tomada por mais sílabas, notas ou passos, esse intervalo de tempo será rotulado de tempo composto.

Pode-se tomar um paradigma das questões relativas às escalas musicais. Para isso, o gênero enarmônico usa a mesma altura em um intervalo composto que o gênero cromático torna não composto. Às vezes o mesmo gênero torna o mesmo intervalo composto e não composto, embora não no mesmo lugar da escala.

O paradigma difere de nosso problema em que o intervalo de tempo se torna não composto ou composto através dos processos de composição ritmica. O intervalo, pelos próprios gêneros ou por seu lugar na escala. Sobre todos os intervalos de tempo não compostos e compostos, deixe-se assim definido.

15. Com o problema assim reconhecido, deixemos que um intervalo dividido por nenhum dos objetos ritmizados seja chamado não composto absolutamente. Da mesma forma, aquele dividido por todos os objetos ritmizados será composto. Parcialmente composto e parcialmente não composto seria aquele dividido por um e não dividido por outro objeto ritmizado. O absolutamente não composto não seria ocupado por mais sílabas, notas ou passos. Absolutamente composto seria aquele ocupado por mais de um tipo de objeto rítmico. Misto, o único que acaba por ser ocupado por uma nota, mas mais de uma sílaba, ou, por uma sílaba e mais de uma nota.

16. Aquilo pelo qual marcamos o ritmo e o tornamos compreensivel para percepção é o pé, ou mais de um.

17. Dos pés, alguns são compostos de dois intervalos de tempo, uma arsis e uma tesis, outros de três, dois arsis e uma tesis ou um arsis e duas tesis, <outros de quatro, dois arsis e duas tesis>.

18. É evidente que não pode haver um pé de um intervalo de tempo, uma vez que um sinal não faz uma distribuição de tempo. Pois não parece que um pé existe sem uma distribuição de tempo ${ }^{10}$.

Que um pé pode ter mais de dois sinais, os tamanhos dos pés nos mostra. Para os pés menores, sendo de um tamanho facilmente apreendido pela percepção, são facilmente compreensiveis através de dois sinais. O contrário acontece com os pés grandes, pois,

\footnotetext{
8 No original em grego: proton men to kronon.

${ }^{9}$ Tempo não composto (simples) e tempo composto: asyntheton e syntheton.

${ }^{10} \mathrm{Pé}$ é um conjunto, nunca um movimento só. O autor permite a subdivisão de pés longos em partes menores.
} 
sendo de um tamanho dificil de perceber, eles exigem mais sinais, pois a extensão de todo o pé, dividida em mais seções, poderia ser mais facilmente compreendido.

Por que não acontece de haver mais de quatro sinais, que um pé, em e por sua própria natureza, faz uso, será explicado mais tarde.

19. Não deve haver mal entendido sobre o que agora está sendo dito, e inferir que um pé nunca deve ter mais que quatro partes ${ }^{11}$. Pois alguns pés são divididos em uma contagem o dobro da quantidade acima referida, e em muitas vezes mais. Mas um pé não é repartido em mais do que o referido montante em si, mas é distribuído em tais divisões pelo processo de composição rítmica. Deve-se ter em mente que os marcadores que mantêm a função de um pé são diferentes das divisões decorrentes da composição rítmica. É para ser adicionado ao que foi dito, além disso, que os marcadores de cada pé permanecem iguais tanto em seu número e em seu tamanho, mas as divisões decorrentes da composição rítmica assumem uma grande variedade. Isso ficará claro no que se segue.

20. Cada pé é limitado por uma lógica ou alogia de um entre duas lógicas reconheciveis à percepção ${ }^{12}$. O que foi dito ficará bem claro assim: suponha que dois pés sejam tomados, tendo o primeiro sua arsis igual à tesis, ambos diseme (dois tempos primários); o segundo com uma tesis de diseme, a arsis a metade. Suponha então que um terceiro pé seja tomado, tendo sua tese igual a ambos, mas sua arsis com uma duração entre a das outras duas arsis. Tal pé tem sua arsis alógica em relação a sua tesis. Essa alogia está entre duas lógicas reconheciveis para a percepção, o igual e o duplo. Isto é chamado de khoreios alógico [ = troqueu].

21. Não se deve errar aqui, não percebendo como o estabelecido e o alógico se incorporam à questão dos ritmos ${ }^{13}$. Assim como nos elementos da melodia, o estabelecido de acordo com a melodia é apreendido, que é primeiro melódico, então reconhecido pelo seu tamanho; Por exemplo, as consonâncias e o tom e as coisas proporcionais a essas coisas. Então há o que é estabelecido apenas de acordo com as proporções de números, o que não é melódico. Assim, nos ritmos devem ser entendidos o estabelecido e o alógico.

Um é apreendido como estabelecido pela natureza do ritmo, o outro apenas pela proporção dos números. A duração do tempo que é considerada estabelecida no ritmo deve ser uma daquelas que caem sob composição rítmica; Então, uma parte estabelecida do pé em que foi colocado. O que é considerado estabelecido apenas de acordo com as proporções de números deve ser entendido como tal, como é o décimo segundo tom em intervalos, e se houver qualquer outra coisa semelhante nas comparações de intervalos.

É claro, pelo que foi dito, que a arsis tomada entre os outros não é proporcional à sua tesis. Pois não há uma medida rítmica comum a eles.

22. Que estas sete distinções entre os pés sejam estabelecidas: primeiro, aquela pela qual eles diferem uns dos outros em tamanho; em segundo lugar, aquela pela qual eles diferem em gênero; terceiro, aquela por que alguns são pés estabelecidos, outros são alógicos; quarto, aquela pela qual alguns são não compostos, outros compostos; em quinto lugar, aquela pela qual eles diferem uns dos outros em divisão; sexto, o que diferem uns dos outros em esquema; sétimo, aquela pela qual diferem pela antítese.

23. Um pé difere de outro pé em tamanho, quando as durações dos pés, que os pés compreendem, são desiguais.

24. No gênero, quando as proporções dos pés diferem uma da outra, como quando uma tem razão de igualdade, a outra de duplicidade, a terceira tem outra proporção rítmica de tempo.

\footnotetext{
11Sobre o máximo de quatro divisões de um pé e as diferenças entre a marcação dada pelo pé e pela subdivisão da composição ritmica. Ao que parece, o processo composicional é artificial em relação à marcação do pé.

${ }_{12}$ Costuma-se traduzir esta noção por razão, irracional, razões, em vez de lógica, alogia, lógicas. Mostra o quanto mudou a forma de tratar a palavra logos, traduzida para o latim como ratio. Originariamente, logos era o dizer-se da Physis, ou seja, o aparecer de tudo que é doação da Physis. Estes dois termos são bastante complexos e são discutidos desde os tempos de Heráclito e Parmênides, pelo menos. Já em Aristóxeno seu significado havia sofrido mudanças, mas não é possivel ainda mensurar o quanto restara na cultura da época de força do sentido originário da palavra logos para pensar uma possivel transição de sentidos.

${ }_{13}$ Números e ritmos: arythmos e rythmos - deve-se entender o ritmo em seu aspecto musical e racional, percebendo suas diferenças.
} 
25. Os alógicos diferem dos estabelecidos por não terem a arsis estabelecida em relação à tesis.

26. Os não-compostos diferem dos compostos por não serem divididos em pés, sendo o composto dividido.

27. Eles diferem em divisão, quando a mesma magnitude é dividida em partes desiguais; Partes desiguais em relação tanto à sua contagem e suas durações, ou em relação a ambos. 28. Diferem uns dos outros em esquema, quando as mesmas partes do mesmo tamanho não estão dispostas da mesma maneira.

29. Eles diferem uns dos outros por antítese, quando têm suas arsis e tesis contrariamente dispostas. Esta distinção estará nos pés que são iguais entre si, mas têm a tese diferente da arsis.

30. Existem três gêneros de pés que admitem uma composição rítmica contínua: o dátilo, o iambo e o peão. O dátilo é aquele de razão igual; o iambo, o dobro; o peão, de um e meio ${ }^{14}$.

31. O menor dos pés é aquele na duração triseme, pois a duração do diseme teria uma marcação completamente comprimida de pés. Aqueles na duração triseme são iâmbicos por gênero. Pois no número três, a única proporção é o dobro.

32. Em segundo lugar são aqueles em duração tetraseme. Estes são datílicos por gênero. Pois nos quatro, há duas proporções, a do igual e a do triplo. Destes, o triplo não é rítmico, o do igual cai no gênero datílico.

33. Em terceiro lugar, de acordo com o tamanho são aqueles na duração pentaseme. Nos de cinco são duas proporções, o quádruplo e o três-para-dois. Destes, o quádruplo não é rítmico, o três-para-dois produzirá o gênero peônico.

34. Quarto são aqueles na duração do hexaseme. Esta duração é comum a dois gêneros, o iâmbico e o datílico, pois em seis há três proporções, o igual e o duplo e o quíntuplo. O último nomeado não é rítmico; Dos outros, a proporção do igual cai no gênero datílico, o do duplo no iâmbico.

35. A duração do heptaseme não tem uma divisão em pés, pois das três proporções recebidas em sete, nenhuma é rítmica. Desses, o primeiro é de quatro a três, o segundo é de cinco a dois, o terceiro, sêxtuplo.

36. Assim, em quinto lugar vêm aqueles na duração octaseme. Estes serão datílicos por gênero, desde que certamente $[\ldots]$

\section{Algumas diferenças de abordagem}

Um trabalho similar realizado por Abdy Williams, no início do século XX, coloca sob uma perspectiva moderna alguns termos utilizados por Aristóxeno e pode agora revelarnos as diferenças de tratamento dos termos no meio musical em um intervalo de um século.

Assim, a sua obra, The aristoxenian theory of musical rythm, tenta conciliar uma prática vigente de sua época com as significações dos termos de Aristóxeno. Observem-se a seguir algumas diferenças entre a presente tradução e o texto de Williams, incluindo algumas observações de cunho prático, tomando em conta análises prévias de obras históricas:

O pé anacrústico era considerado de maior importância para os gregos do que o tético, de acordo com Williams, porque verificou que o primeiro era mais usado. Ele compara o pé simples com o compasso e o pé composto com a frase.

Uma diferença importante deve ser assinalada, em relação à contagem da duração (quantidade) das sílabas longas e breves nos poemas a partir dos metros gregos, nos tempos de Aristóxeno e posteriormente, a partir dos teóricos latinos, que perdura até hoje. Em Aristóxeno, as proporções de duração importam e são apontados (quão longas e breves as sílabas devem ser), enquanto nos estudos latinos apenas diferenciam-se as sílabas longas das breves. 
Quando trata de dátilo choreico (que interpreta com uma semínima e duas semicolcheias), Williams diz que o protos chronos foi dividido e que uma regra foi quebrada. Mas as semicolcheias não o fariam a partir do momento em que entram no papel de protos chronos?

O ensino de Aritóxeno com relação aos chronos protos parece ter durado quase até a idade da música mensural, pois Hieronymus de Moravia, escrevendo em 1250 d.C., diz: "Instans é o menor e indivisivel do tempo em que o som pode ser ouvido clara e distintamente, e isto é o que os antigos chamaram o tempus". (WILLIAMS, 1911, 29.) (Tradução nossa.)

Os gregos usavam dois sistemas de letras para escrever as composições. Um para o canto, outro para os instrumentos. O autor compara com o uso da tablatura para os instrumentos e a linha de canto no sec. XVI. As letras, escritas de trás para frente ou em vários sentidos, mutiladas ou alteradas de várias formas, eram chamadas semeia (sinais). Outros sinais eram adicionados acima das letras para mostrar a quantidade de protos chronos de cada duração, o tempo da música. Um autor anônimo deu as informações das indicações de tempo e de pausa, até o equivalente a cinco protos chronai. Nos tempos, o protos chronos não precisava ser indicado: dois tempos _ ; três _ $\mid$ quatro $\left.\right|_{-} \mid$; cinco $\left.\left.\right|_{-}\right|_{-} \mid$. As pausas eram indicadas $\operatorname{com}^{\wedge}$ para um tempo e o mesmo sinal em cima das indicações de 2, 3, 4 e 5 tempos. Os tempos de pausas geralmente eram usados para completar o pé depois do canto e preenchidos com acompanhamento instrumental. Os sinais costumavam ser omitidos pois geralmente sabia-se os tempos a partir das sílabas e as pausas eram feitas nos finais dos versos, completando o pé. O ponto era usado para acento (stigma), em função similar à barra de compasso, indicando o início do pé, mas também era usado como indicação de sincopação ou colocação artificial do acento, não temos infelizmente informação suficiente para conhecimento preciso do uso do ponto.

Williams ressalta que quando a voz está em jogo várias regras devem ser levadas em conta, mesmo nos tempos atuais, enquanto os instrumentos têm mais liberdade. Observa ainda que para os gregos a variação rítmica era muito importante para evitar o marasmo da repetição dos pés, pois não havia muita complexidade no pensamento da harmonia de várias notas simultâneas que hoje é comum sobre ritmo racional e irracional. No exemplo de Aristóxeno, pode-se calcular um pé de sete divisões, mas esse intervalo entre um tempo primário e um diseme não é preciso. Williams faz a relação com o tempo irregular/irracional/alógico nas pausas onde hoje utilizamos fermata e respirações. Podemos atribuir rubatos instituídos no metro, nessa linha de pensamento. O pé com ritmo irracional era chamado de coreio irracional (alogos chorei).

Erritmia, de acordo com Williams, relaciona-se com a regularidade e simetria dos tempos em uma composição rítmica, o que pode ser de fácil percepção e trazer uma impressão tanto do perfeito quanto do enfadonho. Arritmia, por outro lado, é a imprecisão e assimetria, que está relacionado à falta de controle ou de habilidade no trato com o ritmo. Euritmia se dá quando se alcança um alto grau de satisfação estética. Traçando um paralelo com o estudo de Benveniste sobre ritmo, a forma bela é o que diz este último termo em sua origem ${ }^{15}$. Assim como se pode dizer que há arritmia quando, no momento em que o fenômeno musical se dá, não há percepção de uma forma, ou seja, o sentido musical é dificultado por razões como imprecisão ou aleatoriedade. Erritmia aconteceria quando essa forma é perceptivel.

\footnotetext{
15 De rysmos, tiram-se os compostos omórrysmos, omoiórrysmos, "da mesma forma", omorrysmé, "semelhança"(...) eurrysmós, "de bela forma, elegante", etc. (BENVENISTE, 1976, 365.)
} 


\section{Considerações finais}

Para Aristóxeno, os intervalos de tempo e sua percepção não são os únicos objetos de estudo do ritmo, mas de certa forma são seu princípio fundamental. Este fato em si coloca a questão cognitiva sob outra perspectiva histórica, pois, já em Aristóxeno, o fenômeno e sua percepção são complementares.

O presente trabalho não pretende se colocar como referência de futuros estudos de tradução, mas julga necessário colocar a atenção sobre termos muito utilizados na música e seus sentidos originários.

\section{Referências bibliográficas}

BENVENISTE, Émile. A noção de "ritmo" na sua expressão lingüística. In: Problemas de lingüistica geral. São Paulo: Nacionai/EDUSP. 1976.

HAVELOCK, Eric. A música suprema é a filosofia. In: HAVELOCK, Eric. Prefácio a Platão; Trad. Enid Abreu Dobránzsky. Campinas, SP: Papirus, 1996.

A Revolução da escrita na Grécia e suas conseqüências culturais. Ordep José Serra, trad. São Paulo: Paz e Terra, 1994.

MARCHETTI, Christopher C. Aristoxenus elements of rhythm: Text, Translation, and Commentary with a Translation and Commentary on POxy 2687. Dissertação para preenchimento parcial dos requerimentos necessários para obtenção do grau de Doutor em Filosofia. Nova Jersey: The State University of New Jersey, 2009.

MICHAELIDES, Solon. The music of ancient Greece: an encyclopaedia. Londres: Faber and Faber, 1978.

WILLIAMS, C. F. Abdy. The aristoxenian theory of musical rythm. Cambridge: University Press, 1911.

WINOLD, Allen. Rhythm in twentieth-century music. In: DELONE, Richard et al. Aspects of twentieth-century music. New Jersey: Prentice-Hall, 1975. 